\title{
Nomadic Ecology shaped the highland geography of Asia's Silk Roads
}

\author{
Michael D. Frachetti ${ }^{a}$, C. Evan Smith ${ }^{a}$, Cynthia Traub $^{a} \&$ Tim Williams ${ }^{b}$
}

\section{Summary}

The Eurasian 'Silk Road' is considered one the world's most extensive overland trade networks, yet questions regarding the evolution of its ancient routes and the factors that shaped their geography remain unanswered. This is especially problematic in its vast mountainous stretches, where harsh conditions and terrain are seen as impediments to travel. We present a model that uses highland pasture quality to calculate optimized seasonal herding patterns of nomadic societies, who historically occupied the highlands of Inner Asia (750 m to $4000 \mathrm{~m}$ ). We illustrate variable routes of annual nomadic mobility as "flow accumulations" and aggregating 500 iterations of the model reveals a high-resolution flow network which simulates how centuries of seasonal nomadic herding could shape discrete routes of connectivity across the mountains of Asia. Comparing the locations of known high-elevation Silk Road sites and the geography of these optimized herding flows shows a significant spatial correspondence in mountainous regions. Thus, while routes surrounding lowland, oasis cities may have been influenced by other factors (not tested), our model suggests that the geography of highland Silk Road networks ( $750 \mathrm{~m}$ to $4,000 \mathrm{~m}$ ) emerged slowly in relation to long-established seasonal mobility patterns used by nomadic herders in the mountains of Inner Asia.

aSAIE Laboratory, Department of Anthropology, Washington University in St. Louis, 1 Brookings Drive, CB 1114, St. Louis MO 63130 emails: frachetti@wustl.edu , cesmith50@gmail.com, ct@wustl.edu ${ }^{b}$ Institute of Archaeology, University College London, 31-34 Gordon Square, London WC1HOPY UK email: tim.d.williams@ucl.ac.uk 


\section{Introduction}

Historians and archaeologists agree that Eurasia's overland "Silk Roads" were defined by a complex network of pathways linking trade centers from China to the Eastern Mediterranean and beyond ${ }^{1-3}$. While lowland oases defined the geographic setting for large towns and cities, the vast mountainous regions lying between regional lowlands were an integral part of this transcontinental network ${ }^{4-6}$. Current scholarly attempts to map the Silk Road's pathways have focused on major centers, combining historical (chronological) information with spatial methods to "connect the dots" between sites throughout this lowland and highland system ${ }^{7,8}$. These renderings rely primarily on terrain-based "least cost" travel algorithms to predict likely routes, which has been largely effective in lowland zones where research on economic networks and communication between urban centers is consistent with ease of travel ${ }^{7,8}$. However, data summarized from more than 50 years of research concerning nomadic adaptive strategies in Asia's highland elevations, suggests that "ease of travel" was not the dominant factor dictating mobility across the mountains ${ }^{9}$. Variables fundamental to highland nomadic herding strategies, such as seasonal pasture quality and variation in annual mobility patterns, have not been reliably tested in light of Silk Road geography. Thus, it remains uncertain to what extent mobile pastoralist ecology in highland elevations contributed to the high elevation pathways of the Silk Road, which were essential for the wider network to function. Our model uses variables relevant to mountain nomadism to simulate annual herding pathways across highland Asia without using known Silk Road sites as input. Rather, we compare the resulting "flow" pathways simulated by our model with the historical locations of mountainous Silk 
Road sites, effectively testing the relationship between nomadic mobility and the geography of Silk Road interaction across highland regions of Inner Asia.

Central Asia's geography of expansive deserts, oasis-like inland deltas, vast arid steppes, and high mountain ranges has influenced the evolution of domestic economies and interaction for millennia. The region's first Neolithic farming societies were limited to low foothills of the Kopet Dag mountains ${ }^{10}$, with only minor expansions northward before the $3^{\text {rd }}$ millennium BCE. The extreme aridity of the Kyzyl Kum and Kara Kum deserts confined ancient agricultural economies (both farming and husbandry) to riverways and deltas, eventually channeling the spread of domestic crops (and animals) northward to the rain fed piedmont of the Inner Asian mountains, roughly 5,000 years ago ${ }^{11,12}$. Within a diverse spectrum of nomadic herding economies that developed at this time across Eurasia, vertically transhumant pastoralism emerged as one of the most ancient and successful ecological strategies to exploit the increased productivity of summer highland grasslands in the mountains of Inner Asia ${ }^{13-15}$. From the early $3^{\text {rd }}$ to $2^{\text {nd }}$ millennium BCE, mobile pastoralists fluoresced everywhere across Inner Asia's mountain zones and fostered longstanding interactive spheres that spanned from the Hindu Kush to the highland ranges of the Altai Mountains and eastern Tian Shan in China ${ }^{16-23 .}$

Mobile pastoralists are recognized as important agents of exchange between ancient trade centers, east and west across Asia ${ }^{24-27}$. However, their influence in determining the geography of the routes and social nodes that underpinned historical Silk Road interaction is less explicitly documented and rarely quantified. In an effort to understand if ecologically rooted nomadic mobility strategies in Inner Asia's mountains impacted highland connectivity at a continental scale, we developed an 
environmentally derived Flow Accumulation model that maps seasonally transhumant herding patterns across highland pasture zones (where this adaptation is relevant) and correlates the geography of these evolving pathways with the locations of Silk Road sites across the mountains of Inner Asia.

\section{Modeling nomadic mobility and connectivity across Asia:}

Archaeological and ethnographic evidence shows that for over 4,500 years seasonal herders exploited highland pastures in the summer when grass resources are rich, and return in winter to lower elevations where ecological conditions are favorable during colder months ${ }^{28,29}$. Across Inner Asia, extreme aridity limits intensive lowland herding during the summer, yet highland pastures become more productive and abundant as one moves up to elevations between $1,500 \mathrm{~m}$ and $3,000 \mathrm{~m}$, with a high-altitude limit of roughly $4,000 \mathrm{~m}$, beyond which vegetative growth is restricted (largely) by permafrost and short snow-free periods ${ }^{30}$. Flow Accumulation modeling has been used effectively to simulate local seasonal nomadic migration ranges of Bronze Age pastoralists in highland areas of Kazakhstan, using archaeological and environmental parameters quantified from field-based archaeological survey data ${ }^{31}$.

The 'Pastoralist Participation' or PastPart model (Extended Data, Fig 1; also Supplementary Information) simulates the aggregated seasonal mobility of domestic herd animals across a broad territory straddling Asia's dominant mountain chains including the Hindu Kush (N. Afghanistan), the Pamir (Tajikistan), the Tian Shan (Kyrgyzstan, Kazakhstan, Xinjiang [China]), the Dzhungar (Kazakhstan) and the Altai Mountains (Kazakhstan, Russia, and Mongolia) (Fig. 1). This region has been collectively called the "Inner Asian Mountain Corridor" (or IAMC), describing the 
territory of shared ecology and archaeology that linked Central and East Asian pastoralists and settled communities over the past 4,500 years ${ }^{16,32,33}$. In historical times, this mountain corridor geographically overlaps with the highland territory of Silk Road connectivity and commerce, wherein a range of populations facilitated transcontinental caravan trade and local interactions from antiquity to the early modern era ${ }^{17,34}$.

Briefly setting aside the diverse social factors that influence transhumant pastoralism in regional contexts, broadly documented variables that shape its expression across highland Inner Asia include: 1) seasonal geography of settlement and mobility; 2) grass (fodder) quality and distribution; 3) settlement density and population size; and 4) time. We use these factors to simulate nomadic herding pathways throughout the mountains of Inner Asia and argue that transhumant herding mobility patterns shaped longstanding routes of connectivity which, through time, are reflected in the geography of highland Silk Road networks (750 m to 4,000 m).

Our high-resolution flow model explicitly simulates the influence of natural pasture quality on the flows of domesticated herd animals between elevations of 750 $m$ and 4,000 m, which we take as our modeled elevation "range of interest" (ROI). This elevation range effectively delimitates the lowland and highland boundaries of mountain grassland ecology relevant to highland pastoralist mobility across Asia (Methods and Supplementary Information). Of the 618 known Silk Road sites distributed within our broader study zone, 360 were located outside the modeled elevation ROI (i.e. lower than 750 m or higher than 4,000 m above sea level) (Extended Data Fig. 5a). Lowland oasis regions were dominated by agricultural urban centers for which the variables underlying their connectivity have been shown to be dissimilar to 
those at play in the mountains, where nomadic pastoralism is prevalent ${ }^{35,36}$ (see Supplementary Information for discussion). In addition, modern irrigated agriculture and industrialization in these lowland areas today complicates comparable applications of remote sensing (Supplementary Information). The PastPart model is designed using variables that influence seasonal pastoralist mobility in upland areas, where modern pasture vegetation is not heavily impacted by industrialization (see Methods).

Using low population size and reclassified highland pasture quality as model constants, the accumulation of non-zero flow values defines herding pathways between piedmont settlement zones and highland pastures, whereas zero values represent areas without paths (Extended Data, Fig. 2-4). By iterating our flow accumulation model 500 times, we simulate repeated nomadic migrations with variation through time, introducing parametric changes for each run in terms of winter campsite distribution and the distances and directions of seasonal herding mobility across the ROI (Methods). The resulting map shows a network of pathways with positive flow accumulations, which was then compared spatially with the location of known sites from the Silk Road database $(n=258)$ within the modeled elevation ROI (between $750 \mathrm{~m}$ to $4,000 \mathrm{~m}$ ) (Methods). Since these sites were not factors in the flow model, they serve as an independent proxy to compare highland Silk Road site geography with the cumulative mobility patterns of seasonal pastoralists across the mountains of Inner Asia. To statistically validate this comparison, we also compared flow values with an equal number of randomly generated points $(n=258)$ distributed across the elevation ROI, and iterated this process 200 times. 


\section{Results:}

A single iteration of the PastPart model produces a dendritic pattern of flow accumulations reminiscent of streams, simulating ecologically driven trajectories of herd mobility throughout the elevation ROI (Fig. 2a). Each independent run produces a unique raster map illustrating considerable variation in the geography of flow accumulation from run to run. A pattern of high-magnitude regional flow values (> $30,000)$ begins to emerge after mathematically adding ten iterations of Flow Accumulation (sumFA_10) across the modeled elevation ROI (Fig. 2b). Mathematically summing 500 Flow Accumulation iterations (sumFA_500) generates an extensive network of inter-regional flows, which shape discrete pathways of connectivity across highland Inner Asia (Fig. 2c). The resulting maps simulate the network of pathways that would emerge from the long-term accumulation of highland transhumant mobility across Asia, represented as raster cells with positive flow accumulation values in the aggregate flow maps. Raster cells with a value of zero represent areas where no pathways converge in 500 iterations of the PastPart model.

Out of the 258 Silk Road sites distributed within our modeled elevation ROI, we find that 148 (57.36\%) fall on flow accumulation values greater than zero (Fig. 3a). When values at highland Silk Road site locations were extracted from a statistically buffered flow-accumulation map (created by averaging values of neighboring grid cells a distance of $2 \mathrm{~km}$ from positive flow accumulations, see Methods), 192 (74.42\%) highland Silk Roads sites fall on flow values greater than zero (Fig. 3b). The buffered flow accumulation aggregate simulates the likelihood of spatial variation in grassland distribution through time and the possibility that sites might be built "close" but not “on" pathways (see Methods and Supplementary Information). 
When flow values were evaluated using 200 iterated cohorts of 258 randomly generated points across the modeled elevation ROI (Extended data Fig. 5b, Supplementary Information), a mean number of $73.2(28.37 \%)$ (St. Dev. $=6.92$ ) fall on flow accumulation values greater than zero (Figure 3a). The mean number of random points that fall on flow accumulation values greater than zero rises to 105.5 (40.91\%) (St. Dev. $=7.53$ ) when the flow value at points was evaluated using the statistically buffered flow accumulation aggregate (figure 3b).

The z-score of the counts of positive values extracted by the randomly generated point cohorts shows that the number of highland Silk Road sites falling on pathways simulated by our model is more than 10 standard deviations away from the mean of random points. The $p$-values derived from a one sample t-test comparing the count distribution of positive flow values at randomized points against the number recorded at highland Silk Road sites indicate that highland Silk Road sites are significantly more likely to fall on pathways generated by the PastPart Model than are 200 iterations of randomly generated cohorts of points $(p<.001)$ (see Methods and Supplemental Information).

\section{Discussion}

The first conclusion we can draw from our results is that an extensive network of connectivity emerges as an aggregate effect of seasonal mobility amongst small and geographically sparse mobile herding populations across the highlands of Inner Asia. After 500 iterations, or the modeled equivalent of 20 human generations, flow 
aggregations form a near-continuous geography of "pathways" that discretely connect over $70 \%$ of highland Silk Road sites ( $750 \mathrm{~m}$ to $4,000 \mathrm{~m}$ )(Fig. 4, a-c).

The results of the PastPart model offer an alternative to understanding the geography of the highland Silk Roads on the basis of topographic "ease of travel" and "connecting the dots" between known Silk Road sites (Fig. 5 a-c). The aggregate flow accumulation maps illustrate in high resolution the argument that the mountainous portions of the Silk Road more likely developed as a series of short-distance exchanges, with travelers rarely covering long distances ${ }^{7,15}$. Existing patterns of pastoralist movement through the mountains were rooted in local knowledge of the landscape, while informal or formal access to resources (fodder, water, etc.) was likely significant in the development of this diverse network $37,38,39$. Our model also highlights potential pathways and connectivity in areas where historical Silk Road sites are less known archaeologically, such as west of Narat in Xinjiang China (Fig. 5a). As such, it provides scholars the opportunity to target new regions for Silk Road research and exploration and to revise the history and cartography of interregional interaction on the basis of easily modeled variables (Fig. 5b, c).

The earliest historical sources that describe transcontinental trade networks across overland Asia are dated to roughly $200 \mathrm{BCE}^{5}$. Yet recent archaeological research from the region demonstrates that informal (i.e. pre-bureaucratic) relationships between mobile pastoralists and their neighbors resulted in extensive and complex distributions of commodities, technologies, and ideology, already by 2500 BCE ${ }^{16,40-41}$. Well-documented transmissions of domesticated grains, metallurgical technologies, and other materials and associated cultural practices occurred in the Bronze Age without the driving force of state-structured political authorities ${ }^{42,43}$. Archaeologists 
instead relate these early diffusions to the evolution of interaction networks amongst pastoralist communities, whose seasonal mobility patterns brought them in contact with one another, especially in highland territories 37,44 . Since the PastPart model illustrates how highland nomadic mobility could organically influence the formation of transcontinental connectivity and archaeology places the development of mountain herding economies as early as $2500 \mathrm{BCE}$, we argue that the foundational circuitry of vast trans-Asian networks likely emerged millennia before "Silk Road" interactions were historically documented ${ }^{6}$.

\section{Concluding remarks}

The PastPart model is intentionally agnostic to the many social factors that unquestionably shaped the dynamic interactive history of prehistoric and historical societies along the Silk Road. The aim of our model was confined to simulating the geography of highland nomadic flows as a simple equation between the ecology of seasonal herding mobility and the broad environmental distribution of pasture resources across Inner Asia's mountains. While our model does not fully provide explanations for the economic, institutional and cultural expressions that define the Silk Road archaeologically or historically, it does allow us to illustrate the important influence that small-scale mobility patterns can have in shaping macro scale networks ${ }^{23}$. Indeed, one could speculate that major Silk Road centers east and west of the Inner Asian mountains may not have flourished without locally established channels of nomadic connectivity through this interstitial highland terrain.

At its most fundamental, the PastPart model illustrates the potential ease by which highland herders likely found themselves - through their most basic of 
economic strategies - paving the way for the enduring pathways of Silk Road participation across highland Asia. Historical accounts typically cast large Silk Road oasis cities, political capitals, or market towns as dominant nodes within transcontinental trade and economic networks across Asia ${ }^{1,45}$. The centripetal forces of urban commerce, ideology, and political economy have been widely recognized from ancient sources as the dominant institutional factors underpinning lowland Silk Road evolution ${ }^{2,46}$. Yet these sources also describe the participation of itinerant craftsmen, merchants, nomads, monks, and others whose Silk Road experiences unavoidably took them outside the orbits of these lowland oases into mountainous realms, where alternative logics of mobility and sociality had dominated for millennia ${ }^{23,27}$. This implies that, at least in the highlands, the early geography of movement, connectivity, and interaction was not solely driven by urbanism, since few highland cities are documented in the mountains before the early medieval period ${ }^{7}$.

In its incipient stages, the scale and regularity of highland interaction was not directly comparable to the multi-dimensional economic system of Silk Road trade at its height. Nevertheless, the spatial correlation between longstanding ecologically derived herding flows and the historically diverse range of known highland Silk Road sites (e.g. towns, caravanserais, mausoleums, religious centers, etc.) indicates that highland nomadic mobility intersected with institutional trends that resonated far beyond Asia's mountainous region. The ongoing task of archaeologists, historians, and anthropologists is to reexamine our interpretive assumptions about the scale and evolution of ancient connectivity in light of such modeled potential and seek more nuanced explanations from the regional and chronological details of contextualized data. 


\section{References}

1 La Vaissière, É. d. Sogdian Traders : A History. (Brill, 2005).

2 Hansen, V. The Silk Road : A New History. (Oxford University Press, 2012).

3 Foltz, R. C. Religions of the Silk Road. (St. Martin's Griffin, 1999).

4 Christian, D. Silk Roads or Steppe Roads? The Silk Roads in World History. Journal of World History 11, 1-26 (2000).

$5 \quad$ Whitfield, S. Life Along the Silk Road. (Univ of California Press, 1999).

6 Frachetti, M. in Reconfiguring the Silk Road: New Research on East-West Exchange in Antiquity (eds Victor H. Mair \& Jane Hickman) 41-54 (Univeristy of Pennsylvania Museum of Archaeology and Anthropology, 2014).

7 Williams, T. D. The Silk Roads: an ICOMOS thematic study. (ICOMOS, 2014).

8 Ciolek, T. M. 1999 - present. Old World Trade Routes (OWTRAD) Project. , <http://www.ciolek.com/owtrad.html> (1999-Present).

9 Barnard, H. \& Wendrich, W. in Cotsen Advanced Seminar Series Vol. 4603 (Regents of the University of California, Los Angeles, 2008).

10 Harris, D. R., Gosden, C. \& Charles, M. P. Jeitun: Recent Excavations at an Early Neolithic Site in Southern Turkmenistan. Proceedings of the Prehistoric Society 62, 423-442 (1996).

11 Stevens, C. J. et al. Between China and South Asia: A Middle Asian corridor of crop dispersal and agricultural innovation in the Bronze Age. The Holocene, DOI:0959683616650268 (2016).

12 Miller, N. F., Spengler, R. N. \& Frachetti, M. Millet cultivation across Eurasia: Origins, spread, and the influence of seasonal climate. The Holocene, DOI:10.1177/0959683616641742 (2016). 


\section{Prehistory. 28, 215-253 (2015).}

14 Khazanov, A. M. in Shifts and Drifts in Nomad-Sedentary Relations (eds Stefan Leder \& Bernhard Streck) 163-178 (Dr. Ludwig Reichert Verlag, 2005).

15 Frachetti, M. D. Multiregional Emergence of Mobile Pastoralism and Nonuniform Institutional Complexity across Eurasia. Current Anthropology 53, 2-38 (2012).

16 Doumani, P. N. et al. Burial ritual, agriculture, and craft production among Bronze Age pastoralists at Tasbas (Kazakhstan). Archaeological Research in Asia 1-2, 17-32 (2015).

17 Frachetti, M. D. \& Maksudov, F. A. The landscape of ancient mobile pastoralism in the highlands of Uzbekistan, 2000 B.C.-A.D. 1400. Journal of Field Archaeology 39, 195-212 (2014). 18 Outram, A. K. et al. Patterns of pastoralism in later Bronze Age Kazakhstan: new evidence from faunal and lipid residue analyses. Journal of Archaeological Science 39, 24242435 (2012).

19 Robinson, S. Pastoralism in the Gorno-Badakhshan Region of Tajikistan. Nomadic Peoples 9, 199-206 (2005).

20 Kuz'mina, E. E. in Prehistoric Steppe Adaptation and the Horse (eds Marsha Levine, Colin Renfrew, \& Katie Boyle) 203-232 (McDonald Institute for Archaeological Research, 2003).

21 Possehl, G. L. Vol. 1 537-551 (1979).

22 Potts, D. T. Nomadism in Iran : from antiquity to the modern era. (Oxford University Press, 2014).

23 Di Cosmo, N. Ancient Xinjiang Between Central Asia and China: The Nomadic Factor. Anthropology \& Archeology of Eurasia 34, 87-101 (1996).

24 Frank, A. G. The Centrality of Central Asia. Studies in History 8, 43-97, doi:10.1177/025764309200800103 (1992). 
the Economic and Social History of the Orient 57, 1-43 (2014).

26 Rogers, J. D. Inner Asian States and Empires: theories and synthesis. Journal of Archaeological Research 20, 205-256 (2012).

27 Beckwith, C. I. Empires of the silk road: A history of central Eurasia from the Bronze Age to the present. (Princeton University Press, 2009).

28 Khazanov, A. M. Nomads and the Outside World. Second edn, (The University of Wisconsin Press, 1994).

29 Salzman, P. C. Pastoral Nomads: Some General Observations Based on Research in Iran. Journal of Anthropological Research 58, 245-264 (2002).

30 Sobolev, L. N. \& Pel't, N. N. Kormovye resursy Kazakhstana. (Izd-vo AN SSSR, 1960). 31 Frachetti, M. D. in Digital archaeology : bridging method and theory (eds Thomas L. Evans \& Patrick T. Daly) 128-147 (Routledge, 2006).

32 Jia, P. W., Betts, A. \& Wu, X. New Evidence for Bronze Age Agricultural Settlements in the Zhunge'er (Junggar) Basin, China. Journal of Field Archaeology 36, 269-280 (2011).

33 Liu, X., Reid, R. E., Lightfoot, E., Matuzeviciute, G. M. \& Jones, M. K. Radical change and dietary conservatism: Mixing model estimates of human diets along the Inner Asia and China's mountain corridors. The Holocene, DOI:0959683616646842 (2016).

34 Barfield, T. in Nomads in the Sedentary World Curzon-IIAS Asian Studies Series (eds Anatoly M. Khazanov \& André Wink) Ch. 10, 234-250 (Curzon, 2001).

35 Stride, S., Rondelli, B. \& Mantellini, S. Canals versus horses: political power in the oasis of Samarkand. World Archaeology 41, 73-87, doi:10.1080/00438240802655302 (2009). 36 Angourakis, A. et al. Land use patterns in Central Asia. Step 1: the musical chairs model. Journal of Archaeological Method and Theory 21, 405-425 (2014).

37 Frachetti, M. D. Pastoralist Landscapes and Social Interaction in Bronze Age Eurasia. (University of California Press, 2008). 
and comparative evidence. Cogent Arts \& Humanities 2, doi:10.1080/23311983.2015.1110272. (2015).

39 Yang, J. Transportation, Boarding, Lodging, and Trade along the Early Silk Road: A Preliminary Study of the Xuanquan Manuscripts. Journal of American Oriental Society 135, 421-432 (2015).

40 Spengler, R. et al. Early agriculture and crop transmission among Bronze Age mobile pastoralists of Central Eurasia. Proceedings of the Royal Society B 281, 20133382, doi:10.1098/rspb.2013.3382 (2014).

41 Mei, J. Qijia and Seima-Turbino: the question of early contacts between northwest China and the Eurasian steppe. Museum of Far Eastern Antiquities bulletin, 31-54 (2003). 42 Honeychurch, W. Alternative Complexities: The Archaeology of Pastoral Nomadic States. Journal of Archaeological Research 22, 277-326 (2014).

43 Rogers, J. D. The Contingencies of State Formation in Eastern Inner Asia. Asian Perspectives 46, 249-274 (2007).

44 Brosseder, U. \& Miller, B. K. in Bonn Contributions to Asian Archaeology (ed Jan Bemmann) 653 (Vor- und Frühgeschichtlich Archäologie Rheinische Friedrich-WilhelmsUniversität Bonn, Bonn, 2011).

45 Chase-Dunn, C. et al. Middlemen and Marcher States in Central Asia and East/West Empire Synchrony. Social Evolution \& History 9, 52-79 (2010).

46 Whitfield, S. Life Along the Silk Road. (Univ of California Press, 2015).

Supplementary Information is linked to the online version of the paper at www.nature.com/nature. 


\section{Acknowledgements}

Funding for research at the SAIE laboratory was provided by Washington University in St. Louis (PI. Michael D. Frachetti). Cody Copp and Mollie Webb provided assistance with modeling and coding in the SAIE laboratory and GIS laboratory of Washington University in St. Louis. Christina Chady assisted in copy editing. An early version of the PastPart model was presented at the Advanced Seminar "New Geospatial Approaches in Anthropology" at the School for Advanced Research, March 6-10, 2016. Dr. Patrick Daly, Dr. Ron Pinhasi, Dr. Greger Larson, and Dr. David Meltzer provided commentary on drafts of this article.

\section{Author Contributions:}

M.D.F. conceptualized the research, designed the spatial model, carried out analysis and interpretation of the results, and wrote the manuscript with input from C.E.S., T.W., and C.T. C.E.S. carried out spatial modeling and script coding in ArcGIS and Python and contributed to analysis and interpretation of the results. T.W. provided the Silk Road site database and contributed to analysis and interpretation of the results. C.T. carried out statistical analysis of the results.

\section{Author Information:}

\section{Data Availability}

The full PastPart model script and ArcGIS model flowchart, as well as all required datasets and statistical output tables are available and free for download as Supplementary Information online. Any additional output data are available upon 
request from the SAIE laboratory server at Washington University in St. Louis, with permission from the corresponding author.

Reprints and permissions information is available at "www.nature.com/reprints".

The authors declare no competing financial interests.

Correspondence and requests for materials should be addressed to Michael D.

Frachetti (frachetti@wustl.edu). 


\section{Figure Legends:}

Figure 1. Geography of Inner Asian study zone (in color) and location of main Silk Road cities across Asia $\left(55^{\circ} \mathrm{N} 60^{\circ} \mathrm{E}, 30^{\circ} \mathrm{N} 60^{\circ} \mathrm{E}\right.$, and $\left.30^{\circ} \mathrm{N} 100^{\circ} \mathrm{E}, 55^{\circ} \mathrm{N} 100^{\circ} \mathrm{E}\right)$.

Figure. 2. Flow Accumulation pathways generated by the PastPart Model between highland pastures (green) and winter campsite (blue) zones (750 m to 4,000 m): (a) Detail of a single iteration of flows; (b) Detail of 10-iteration aggregate of flow accumulations; (c) Detail of 500-iteration aggregate of flow accumulations.

"Randomized settlements" refer to the 5000 randomized points used in generating each iteration of flow accumulation in the PastPart model (a single iteration of points is shown).

Figure 3: Comparative percentages of non-zero values extracted from the PastPart model using 200 cohorts of 258 randomly generated points (left) vs. 258 actual Silk Road sites (arrow) within the modeled elevation ROI (750 m to 4,000 m).

a) Values extracted from the aggregate of 500 iterations of flow accumulations (mean percentage of random pts with non-zero values $=.2837$ vs. Silk Road sites .5736 , Zscore $>10$ ), One sample t-test, $p<.01$ (Supplementary Info, Source Data). b) Values extracted from the statistically buffered aggregate of 500 iterations of flow accumulations (mean percentage of random pts. $=.4091$ vs. Silk Road sites .7442 , Zscore $>10$ ), One sample t-test, $p<.01$ (Supplementary Info, Source Data). Arrow indicates the percentage of non-zero values extracted at known Silk Road sites in the modeled elevation ROI. 
Figure 4. Geographic correspondence between known highland Silk Road sites (750 m to 4,000 m elevation) and 500 aggregated simulated flow accumulations of the PastPart model. Detailed sub-regional maps (a-c) illustrate the magnitude of flow accumulation values extracted at Silk Road sites located within the modeled elevation ROI. Point numbers correspond to site names listed in the field "ObjectID_1" found in the Silk Road dataset (Source Data).

Figure 5. Comparative geography of proposed Silk Road corridors calculated using least-cost (ease-of-travel) algorithms (black and blue lines) to connect known archaeological/historical sites ${ }^{7}$ (Source Data link) and the simulated herding flow pathways from 500-aggregate runs of the PastPart model (yellow and red "flow" aggregates). Notable differences between modeled "ease-of-travel" corridors and ecologically derived flow accumulation pathways are visible in the inset detail maps (ac). PastPart flow accumulation pathways illustrate in panel (a) likely highland Silk Road routes between Narat (61) and Karkara (18) and alternative highland passes to the immediate east of the Turugart Pass (31) toward Kashgar (133); (b) a potentially undocumented corridor of the Silk Road into the Tibetan Plateau to the south of Dunhuang (406) (China); (c) a number of alternative networks of connectivity across the western Himalaya and Pamir Mountains, for example diverse routes from Kashgar (133) to Tashkurgan (345). 


\section{Captions for Extended Data figures:}

Extended Data, Figure 1. Flowchart of the PastPart model workflow yeilding a summed aggregate of 500 runs of Flow Accumulation within the modeled elevation ROI (750 m-4,000 m). Inputs: 1) model source directory 2) NDVI data. 3, 4, 5, 6) DEM images. 7, 8, 9, 10) model parameter files: settlement_class.txt, sheep_class.txt pasture_class.txt, vegetation_class.txt. Outputs: 1) processing geodatabase 2) results geodatabase 3 ) NDVI converted to GRID format. 4, 5, 6, 7) DEM images converted to GRID format 8) study area DEM 9) study area NDVI 10) probablity surface 11) cost surface 12) weight raster 13) 5000 random spatially balanced points 14) cost distance raster 15) flow direction raster 16) flow accumulation raster. Processes: 1 ) Create geodatabases 2 ) load files to processing geodatabase 3 ) mosaic DEM files and clip images to study area 4) create model inputs: a) classify study area DEM using settlement_class.txt to create probability surface b) classify NDVI using vegetation_class.txt create vegetation priority raster c) classify DEM using sheep_class.txt to create highland flow weight raster 5 ) generate spatially balanced random settlements $(n=5000)$ 6) calculate cost distance 7) calculate flow direction 8) calculate flow accumulation 9) sum flow accumulation rasters. Variables: 1) number of iterations 2) Current iteration value 3 ) number of output points. Unused data: 1) output backlink raster $\mathbf{2}$ ) output drop raster.

Extended Data, Figure 2. Detailed view of the seasonal highland/lowland division of the elevation range of interest (ROI) (750 m to 4,000 m). Highland "summer" zones (green) are defined from 1500m-4000m above sea level, and "winter" campsite zones (blue) are defined from 600m-1500m above sea level. Prominent Silk Road cities are mapped for geographic reference.

Extended Data, Figure 3. Detailed view of one run of spatially balanced random points distributed throughout in the winter campsite elevation. In total, 5000 points were generated (for each of the 500 runs the PastPart model) in the winter campsite settlement elevation range (600 $\mathrm{m}$ to $1500 \mathrm{~m}$ ) across the entire study zone (map inset). Each iteration of sites recalculates (along with the reclassified vegetative weight raster) the "cost distance" map across the modeled elevation ROI (750 m to $4,000 \mathrm{~m})$. 
Extended Data, Figure 4. Upper) Detail of reclassified vegetative weight raster (veg_priority) overlaid with one run of randomized foothill points $(n=5000)$ simulating winter campsites. Lower) Detail of the cost distance raster $\left(C D \_x\right)$ calculated using 5000 randomized "winter settlement" points and the vegetative weight raster. Each of the 500 iterations of new points changes the geographic distribution of "low cost" travel between weighted pasture zones $(750 \mathrm{~m}$ to $4,000 \mathrm{~m}$ ) and the lower elevations effectively causing variations in the flow accumulations from pastures to hypothetical settlements in the foothills with each iteration.

Extended Data, Figure 5. Upper) Distribution of known Silk Road Sites ( $n=258)$ in relation to the modeled elevation $\mathrm{ROI}$ (750 m to 4,000 m, in grey); Lower) Distribution of a single run of randomized test points $(n=258)$ generated in relation to the modeled elevation ROI (in grey). 200 runs of random test point cohorts were calculated in the modeled elevation ROI. 


\section{Methods}

\section{Modeling Pastoralist mobility as flow accumulation: Overview}

The ‘Pastoralist Participation' (PastPart) model provides a quantitative simulation of the macro-regional footprint of transhumant (mountain) pastoralism across mountainous regions of Inner Asia. The model was designed using the Geographic Information Systems software ArcGIS (ESRI) and then executed in Python utilizing ArcGIS's native Python geoprocessing tools. The full programming codes and datasets necessary for executing the PastPart model are presented as a unified Python script in Supplementary Information.

The PastPart model adapts the hydrological tool Flow Accumulation in ArcGIS to simulate seasonal herding "flows" between rich mountain pasture zones and a delimited lowland winter settlement zone within a modeled elevation "range of interest" or ROI (750 m to $4000 \mathrm{~m}$ ). This ROI encompasses archetypical elevation zones of seasonal settlement and highland pastures historically documented amongst Inner Asian transhumant herders (Supplementary Discussion).

To start, we populated the representative lowland elevation zone with 5000 randomized points to simulate winter nomadic campsites across the whole study territory. We then generated seasonal herding flows from rich highland pastures toward these lowland points using the relative productivity of mountain grassland types (in terms of pasture fodder quality) as the determining factor for direction and distance from the highlands toward the randomly generated points. We iterated this process 500 times, each time using a newly randomized distribution of lowland points to recalculate the parameters of flow accumulation from $4,000 \mathrm{~m}$ to the 
highland/lowland boundary of $750 \mathrm{~m}$, effectively simulating 500 years of herding mobility across the ROI.

Next, the iterations of simulated flow accumulation were summed mathematically, resulting in aggregated flow maps that amplify the predominant geography of high-magnitude segments of herding flows through time. Aggregate flow maps were calculated using 10 summed iterations (sumFA_10) and 500 summed iterations (sumFA_500) for comparison and analysis.

Using an independent database of all known Silk Road sites $(n=618)$ that fall within the wider study zone we mapped the actual site locations over the aggregate of 500 flow maps (sumFA_500). Values were extracted from the aggregated flow accumulation pathways at each point that fell within the modeled elevation ROI ( $n=258$, Extended Data, Fig. 5), allowing us to test the geographic overlap between the simulated herding flow accumulations and actual locations of the known highland Silk Road sites within the modeled ROI. To account for variation through time, the overlay and value extraction process at highland Silk Road sites was repeated using a "buffered" aggregate flow accumulation map as well, for which flow values were averaged at a distance of two grid cells around the positive flow accumulations (below).

Finally, we generated 200 iterations of spatially balanced random points using the same geographic extent of the modeled elevation ROI and same number of points as the known highland Silk Road sites ( $n=258$, Extended Data, Fig. 5). Each run of random points was sequentially draped over the aggregate flow accumulation map and the buffered flow accumulation map, and flow values were again extracted at each point. We then tabulated the number of sites with extracted values greater than 
zero (and those equal to zero) for each run of the 258 random test points. The range of percentages of random sites distributed across the elevation ROI that intersect with zero and non-zero values was calculated for all 200 runs and statistically compared with the observed percentage of hits using actual highland Silk Road sites.

\section{Base datasets: Generating lowland and highland mask rasters}

The first step in mapping seasonal territories across the modeled ROI is to define discrete zones of winter lowland settlement and highland summer pastures (Extended Data, Fig.1). The lowland settlement area was calculated using four Global Multi-Resolution Terrain Elevation Data (GMTED2010) with a pixel resolution of 30arcs seconds (roughly $1 \mathrm{~km}$ ). These four raster datasets were joined using the Mosaic tool in ArcGIS and then the map extent was constrained to the boundaries of the study zone, reducing file size and operative efficiency (Fig. 1). The elevation values of the clipped DEM were reclassified in ArcGIS using the Reclassify tool. Cell elevation values from $600 \mathrm{~m}$ to $1,500 \mathrm{~m}$ were reclassified to a value of " 1 " and all other elevations to "Nodata". The positive values of this raster were then reclassified again to a value of 0.5 for use as a "probability mask" for random point generation. This mask raster dictates that each pixel has a 50/50 likelihood to receive a random point per iteration of the model (see "creating random lowland settlements" below).

The clipped DEM raster was also used to create an elevation mask to delimit summer pasture zones using the same Reclassification tool, this time reclassifying elevation ranges between $750 \mathrm{~m}$ to $4000 \mathrm{~m}$ to the value " 1 ". The resulting output raster maps include a winter lowland probability mask (settle_zone) that defines the area to contain winter settlements, and a summer highland mask (graze_msk) for use 
in generating a vegetative cost surface (below). The territorial interface between winter and summer zones is between $750 \mathrm{~m}$ and $1,500 \mathrm{~m}$ elevation.

\section{Base dataset: lowland winter settlements}

Based on elevations of archaeologically and historically documented pastoralist campsites in the Dzhungar Mountains of SE Kazakhstan and the Malguzar Mountains of Uzbekistan ${ }^{17,31,44,50}$, we populated the winter lowland raster (settle_zone) with 5,000 randomly placed points using a Spatially Balanced random point generator tool in ArcGIS (Extended Data, Fig. 3; Supplementary Information). The randomized settlement generation was iterated 500 times. The resulting point file (settle_x) represents hypothetical "winter" lowland settlement locales, where " $x$ " refers to the specific iteration of random points. The Spatially Balanced point generator determines the location of points without any discriminating factors other than elevation and the $50 \%$ probability mask applied to each cell. Each random point was minimally separated from the next by a Euclidian distance of $1000 \mathrm{~m}$.

\section{Base dataset: vegetation cost surface using NDVI}

Landcover types within the elevation ROI were derived from a $250 \mathrm{~m}$ resolution, global Normalized Difference Vegetation Index (NDVI) image. This data set is a 7-day average of NDVI values calculated from multispectral eMODIS imagery taken in the month of August $2008^{47}$. August was selected since late summer is the time of maximum pasture productivity across most of the study zone (Supplementary Information). The geographic extent of the NDVI image (NDVI_08) was clipped to our study zone boundaries making it smaller, more manageable, and relevant to our model ROI. We 
used the highland "graze_msk" raster to select those NDVI value ranges that fall within the modeled elevation ROI and the resulting values were classified using 'geometric interval sampling' of the clipped eMODIS NDVI image, with heads-up correction of value-ranges based on botanical cohorts at known elevation boundaries and corresponding field documentation of grassland composition in test areas across the study zone ${ }^{48}$ (Supplementary Information). The NDVI value ranges within the ROI were reclassified in ArcGIS and assigned relative values of 1, 3, 12, 25, 100, or 200 according to relative fodder quality and range productivity of highland grassland mosaics (such as mountain meadows, alpine meadows, arid steppe etc.) at various elevations recorded across Inner Asia ${ }^{37}$ (Extended Data, Fig. 4). The reclassified NDVI value ranges are as follows:

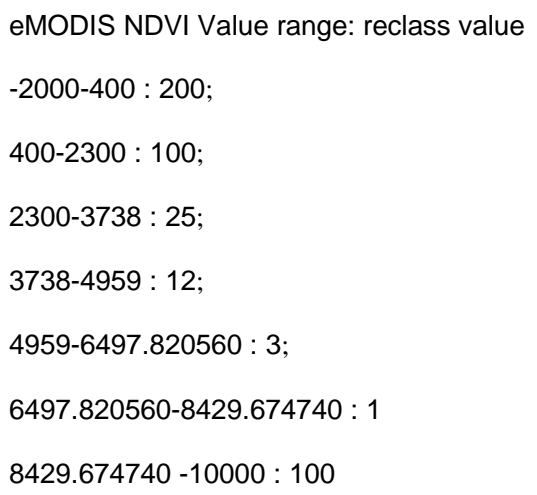

The reclassified landcover weight raster (veg_priority) was then exported and used as a constant dataset in subsequent steps of the PastPart model (Supplementary Information).

\section{Modeling Flow Accumulation}

The Flow Accumulation algorithm in ArcGIS uses a recursive calculation to add values to grid cells based on a "flow direction" raster, which is typically derived from a 
cost surface or Digital Elevation Model. In hydrological modeling, it is typical to use reclassified topographic factors (i.e. elevation, slope, etc.) as a cost surface to derive flow direction. In modeling a cost surface for hydrological flows high elevation would be classified as more costly than low elevation, so water would flow downslope. Conceptually, of course, the cost surface and flow direction can be derived from any set of weight parameters or values.

\section{Iterating Cost Distance, Flow Direction, Flow Accumulation.}

The first step in calculating flow accumulation is to generate a cost distance map, using the Cost Distance tool in ArcGIS. The Cost Distance tool calculates a weighted travel coefficient for each grid cell between selected points. For each iteration of the model $(x)$, we used the lowland settlement points (settle_x) along with weighted vegetation raster (veg_priority) to quantify a corresponding cost distance of travel (CD_x) across the elevation ROI (Extended Data, Fig 4).

The cost distance raster $\left(C D_{-} x\right)$ is subsequently used as an input for the Flow Direction tool in ArcGIS. This step generates a flow director raster $\left(F D_{-} x\right)$ with direction values assigned for each grid cell, which define the likelihood of one of eight possible directions that a given cell can flow toward the next cell, according to the least cost.

The flow direction raster $\left(F D_{-} x\right)$ is then used as input for the Flow Accumulation tool in ArcGIS, along with an optional 'weight raster' that loads source grid cells with a constant value. In our case, we calculated a weight raster (sheep_100) by assigning a value of 100 to pixels from the two best classes of highland pasture (values 1 and 3 in veg_priority). Conceptually this assigns 16 units (of 
figurative herd animals) per hectare (grid cell size is $250 \times 250 \mathrm{~m}$, or $6.25 \mathrm{ha}$ ) - a value consistent with a (low) average range capacity for Inner Asian highland grasslands ${ }^{48}$. Using the constant weight raster (sheep_100) and the flow direction raster (FD_x) as input to the flow accumulation tool, a hypothetical count of 'animals' flowing from the best pastures into each cell across the ROI. Since distance was calculated in reference to the 5000 low elevation settlements (settle_x), the resulting flow accumulation values in each cell illustrates the likely convergence of flow into each cell toward the lowlands with preference toward quality pasture, until flow is limited by uniformly high cost (reverse flow is not allowed).

\section{Modeling flows through time:}

The binary division of seasonal occupation into two discrete elevation ranges generates a condition whereby each run of the model reflects the potential flows of herds within a theoretical year (i.e. one seasonal migration of highland to lowland travel or vice versa). The PastPart model was iterated 500 times $\left(f^{x(1 \rightarrow 500)}\right)$ to reflect 500 unique yearly flow patterns of seasonal migration. For each $f^{x}$ a new distribution of randomized settlements (settle_x) was generated for use along with the vegetative weight raster (veg_priority) as input to calculate iterations of the Cost Distance $\left(C D \_x\right)$, Flow Direction $\left(F D_{-} x\right)$, and Flow Accumulation $\left(F A_{-} x\right)$ rasters. A Python script was then used to access the project geodatabase and sum the individual runs of the model, producing aggregated flow rasters (Supplementary Information). Examples of 10 (sumFA_10) and 500 (sumFA_500) mathematical aggregates were produced for analytical purposes (Fig. 2; Extended Data, Fig. 5). 


\section{Statistics: Silk Road locations vs. random points:}

To quantify the spatial correspondence between independently documented Silk Road sites and simulated flows from the PastPart model, we compiled a database of all known georeferenced Silk Road site locations from the Old World Trade Routes (OWTRAD) and the ICOMOS thematic study archives ${ }^{7,8}$. Silk Road sites located outside the extent of our general study zone (see Fig. 1) were removed from the dataset, leaving a total of 618 known locations in the functional database (the table of Silk Road sites is available for download online in Supplementary Information). We then draped these sites over the sumFA_500 flow accumulation raster map and extracted flow magnitude values at each site using the Extract to Point function in ArcGIS (using the interpolate at point option). Given that the PastPart model only generates flow accumulations within the modeled elevation ROI (between $750 \mathrm{~m}$ and 4,000 m), we discarded from analysis those sites that lie outside the possible range of the simulated flows, leaving a total of 258 sites within the modeled elevation ROI as representative of "highland" Silk Road geography.

Next we generated 200 unique iterations each consisting of 258 random points using the Create Spatially Balanced Random Points function in ArcGIS, defined by a spatial probability mask equal to the extents of the modeled elevation ROI (roi_prob, value $=.5)($ Extended Data, Fig. 5). We then extracted flow accumulation values for each iteration of random points $(\mathrm{n}=258)$ from the sumFA_500 flow map using the Extract to Point function, described above. For each cohort of random points within the ROI, we again tabulated the percentage of points with no flow correspondence (value $=0$ ), and those with positive correspondence (value $>0$ ). Non-zero flow values reflect cells where at least two cells flow together, thus even small positive values represent the 
furthest extent of flow pathways - or in terms of the model - the first convergence of otherwise uniformly distributed herd animals (Supplementary Discussion).

\section{Calculating a statistically "buffered" map of aggregated flow accumulations:}

Our methodology also aims to accurately represent the impact of variation in the model parameters-such as shifts in pasture resources and changing mobility strategies through time - on the geography of flow accumulations, as well as the fact that the Silk Road site database has inherent geo-positional error that cannot be assessed statistically due to the diversity of sources for the data. Many sites in the database have a qualitative "reliability rating" that assesses the accuracy of their latitude and longitude coordinates, but without ground-truthing each site, we take the reported coordinates a priori.

To account for such potential errors, temporal variation, as well as the fact that relevant sites might be located "near" but not directly "on" a modeled flow pathway, we calculated Focal Statistics at a distance of two grid cells $(\sim 2 \mathrm{~km})$ around each cell in the sumFA_500 raster with a non-zero flow value (Supplementary Information). We used the Focal Statistics too in ArcGIS to calculate the mean value of each cell within the search radius and then generated a new raster (FocStat). The resulting map of illustrates the geographic effect of $2 \mathrm{~km}$ buffer zone of positive values around the original courses of non-zero flow accumulations. Using the Extract to Points tool we repeated the process of extracting flow values from this "buffered" Focal Statistics raster (FocStat), again using the 258 Silk Road sites and each of the 200 iterations of 258 randomized test points within the modeled elevation $\mathrm{ROI}$. 


\section{Comparing model performance between known Silk Road sites and randomized}

\section{locations:}

We calculated the percentages of positive flow values extracted from both highland Silk Road sites and from each of the 200 runs of randomized points (Fig. 3a, b, Supplementary Information). Since we can only accurately assess the probability that 258 actual Silk Road sites fall along a path within our study zone (since these are the only sites known), we used a similarly scaled dataset for comparison, with the same potential for distribution. Thus, statistically, both datasets have a theoretically equal "spatial" potential to be located on (or off) a path in the (same) analyzed area. In both cases, sites with positive values represent the locations that geographically intersect with the aggregated flow accumulation map (sumFA_500) or the buffered aggregated flow accumulation raster (FocStat of sumFA_500), respectively.

Using these data, we calculated the mean counts and percentages of non-zero flow accumulation values from the 200 runs of randomized sites. For example, random run 7 had 77 observations with flow accumulation values greater than zero (out of 258 randomized points) or $29.84 \%$ direct hits on the aggregated flow accumulation map (sumFA_500) (Supplementary Info). The same randomized point run 7 had 109 observations with values greater than zero out of 258 randomized points, or $42.25 \%$ hits on the buffered aggregated flow accumulation raster (FocStat of sumFA_500).

We then used the distribution of positive values from the randomized points to compare with count and percentages of positive flow accumulationvalues recorded at the highland Silk Road dataset and computed a Z- score. As an additional comparison, we performed a one-sample t-test using both counts and percentages of non-zero 
values from the 200 runs of randomized point in the ROI and the actual percentage of non-zero values from the Silk Road dataset (Fig. 3,ab).

\section{References:}

47 Jenkerson, C. B., Maiersperger, T. \& Schmidt, G. eMODIS: A user-friendly data source: U.S. Geological Survey Open-File Report 2010-1055 (2010).

48 Frachetti, M. D. Bronze Age pastoral landscapes of Eurasia and the nature of social interaction in the mountain steppe zone of Eastern Kazakhstan Unpublished Ph.D. Thesis, University of Pennsylvania, (2004). 